\title{
A METHOD FOR MEASURING THE SENSITIVITY OF BUILDING STRUCTURAL MEMBERS TO FIRE DECAY PHASES
}

\author{
Thomas Gernay
}

\author{
The National Fund for Scientific Research, Structural Engineering Department, Univ. of Liege, Belgium \\ correspondence: Thomas.Gernay@ulg.ac.be
}

\begin{abstract}
Firefighters face a major threat when intervening in a building during a fire: the possibility of structural collapse during the cooling phase of the fire, or soon thereafter. At present, this threat is amplified by the fact that the behaviour of structures after the time of peak gas temperature is not well understood, and is not taken into account in the design. This work presents an analysis of the behaviour of different structural members under natural fires, and develops a method for characterizing their sensitivity to fire decay phases. Thermo-mechanical numerical simulations based on the non-linear finite element method are conducted using the parametric fire model of the Eurocode to represent natural fires. The results show that, for all the members (a column, a beam) and materials (reinforced concrete, steel and timber) that are studied here, structural failure during or after the cooling phase of a fire is a possible event. The major factors that promote delayed structural failure are thermal inertia and the constituting material of the member. A method, based on a new indicator, is proposed for quantifying the propensity to delayed failure for structural members under natural fire. This work enhances the understanding of the behaviour of structures under natural fires, and has important implications for the safety of fire brigades and of people responsible for making a building inspection after a fire.
\end{abstract}

KEYWORDS: natural fire; structures; performance-based design; decay phases; DHP.

\section{INTRODUCTION}

In a performance-based approach, the fire models used in the analysis aim to capture a realistic representation of the fires that may occur in a building. The fire models therefore include the successive fire development stages until burnout, rather than consisting in continuously increasing time-temperature curves (as in the standard ISO fire). However, the effects of these realistic fires on the structural response, and specifically the effects of the decay phases, are not yet fully understood. Recent building collapse events during or after the decay phase of fires have highlighted the paramount importance of filling this knowledge gap.

Little research has been carried out on the behaviour of structures after the time of maximum temperature, and has focused mainly on residual load-bearing capacity. However, more attention should be brought to the behaviour of structures during and right after the cooling phase of the fire, because the structure is vulnerable in these phases during which the elevated temperature has not yet dissipated. In addition, structural failures arising during these decay phases pose a serious threat to firefighters. Therefore, this research focuses on analyzing the response of structures in the decay phases of a natural fire. To allow for comparative analyses and quantification of the response, a novel indicator (i.e., a measure of performance) is proposed. The paper describes the method for deriving the indicator and applies it for assessing the performance of different structural members under natural fires.

\section{NUMERICAL ANALYSIS OF STRUCTURAL MEMBERS UNDER NATURAL FIRE}

\subsection{GeOMETRY AND SECTION PROPERTIES}

This study considers the following building structural members: a reinforced concrete ( $\mathrm{RC}$ ) column, a protected steel column, and a timber beam.

(1.) An RC column $4 \mathrm{~m}$ in length is exposed to natural fire on its four sides. The column is simply supported at both ends, with no restraint in thermal expansion. A sinusoidal imperfection with amplitude of L/300 is introduced along the column length. It is submitted to a vertical load applied at the centre of the top section. The column has a square cross section with sides of $450 \mathrm{~mm}$, with 12 rebars $16 \mathrm{~mm}$ in diameter and a concrete cover of $30 \mathrm{~mm}$. The concrete compressive strength and the steel reinforcement yield strength at ambient temperature are equal to $30 \mathrm{MPa}$ and $500 \mathrm{MPa}$, respectively. The maximum compressive load at the beginning of the fire (i.e., the capacity at ambient temperature) is $6338 \mathrm{kN}$. The column has fire resistance of 120 minutes when loaded at $50 \%$ of its maximum compressive load at the beginning of the fire, i.e., a $50 \%$ load ratio (LR).

(2.) An HEB 400 steel column in S355 is exposed to natural fire on its four sides. The column is $4 \mathrm{~m}$ in length, it is simply supported at both ends, and it has a sinusoidal imperfection with amplitude of $\mathrm{L} / 300$. Flexural buckling about the weak axis of the 


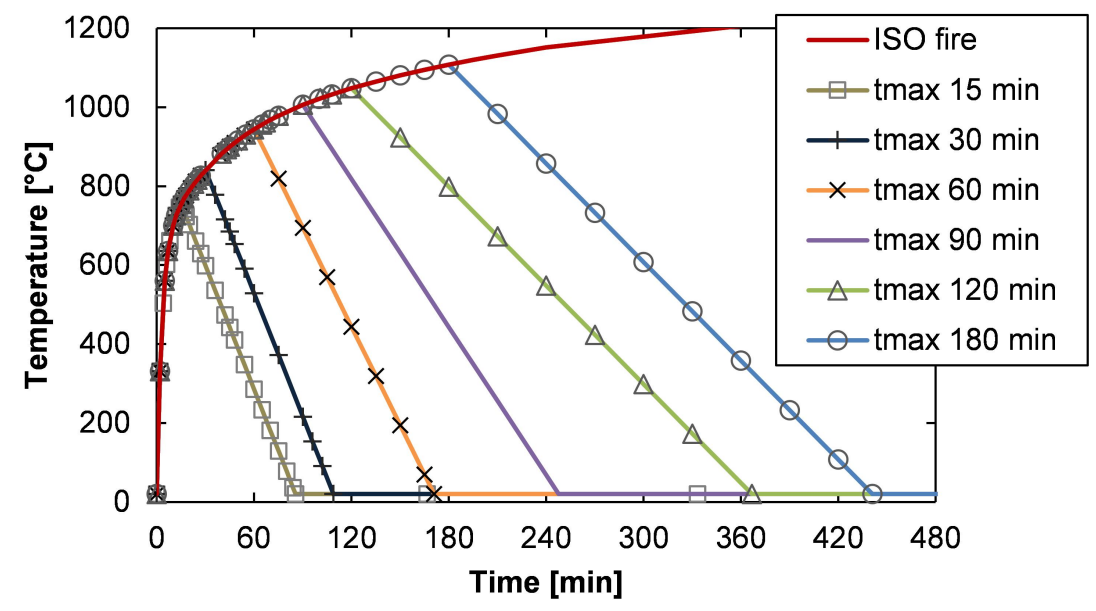

Figure 1. Eurocode Parametric Fire Model for Natural Fire.

section was prevented. It is submitted to a vertical load applied at the centre of the top section. The maximum compressive load at the beginning of the fire is $6256 \mathrm{kN}$. The column is analysed with two different thermal protections. In the first case (P1), the applied thermal protection provides fire resistance of 60 minutes under a $50 \%$ applied load ratio. In the second case (P2), it provides fire resistance of 120 minutes under $50 \%$ applied LR (i.e., similar to the fire resistance of the RC column). This latter fire resistance is achieved using a thickness of $20 \mathrm{~mm}$ of sprayed fire-resistive material (SFRM) with the following thermal properties: thermal conductivity $0.12 \mathrm{~W} / \mathrm{m} \mathrm{K}$, specific heat $1200 \mathrm{~J} / \mathrm{kg} \mathrm{K}$, specific mass of the dry material $350 \mathrm{~kg} / \mathrm{m}^{3}$, water content $20 \mathrm{~kg} / \mathrm{m}^{3}$.

(3.) A softwood timber beam, simply supported with a $4 \mathrm{~m}$ span, is exposed to natural fire on 3 sides. The beam cross-section is rectangular with a height of $0.60 \mathrm{~m}$ and a width of $0.30 \mathrm{~m}$. The applied load is uniformly distributed on the beam, and is maintained constant during the fire. The Young's modulus was taken as $11 \mathrm{GPa}$ and the characteristic bending strength was taken as $24 \mathrm{MPa}$, at ambient temperature.

\subsection{MODEL ASSUMPTIONS}

The adopted model for natural fires is the parametric fire model from Eurocode [1]. It is chosen to set the value of factor $\Gamma$ at 1.0 in the model, which makes the heating phase of the time-temperature curve of this natural fire model approximate to the standard ISO curve. Hence, the only varying parameter in the natural fire model is the duration of the heating phase $t_{\text {max }}$. Figure 1 shows the time-temperature curves for different values of $t_{\max }$.

The study is conducted using non-linear finite element (FE) analysis. SAFIR software [6] is used for the analysis of the heat transfer processes and the thermomechanical behaviour of the member. First, a twodimensional thermal FE analysis is conducted for the
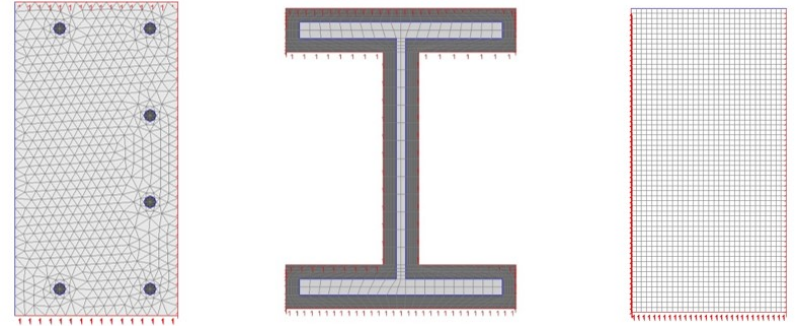

Figure 2. Sections of the RC column (left), the HEB400 steel column (centre) and the timber beam (right). For the RC column, half of the section is modelled, taking advantage of symmetry.

heated member using fiber discretization of the crosssection, see Figure 2. Then, a structural analysis is performed using three-noded, two-dimensional beam elements. The time-temperature evolution in each fiber results from the previously conducted thermal analysis. The structural analysis takes into account geometrical and material non-linearity, including large deflections.

The thermal properties of steel and concrete in the heating phase are taken from the Eurocode [3]. Where concrete is used, siliceous concrete is chosen, with a density of $2400 \mathrm{~kg} / \mathrm{m}^{3}$ and a water content of $48 \mathrm{~kg} / \mathrm{m}^{3}$. The emissivity is taken as 0.7 and the coefficient of convection between concrete and the air is $35 \mathrm{~W} / \mathrm{m}^{2} \mathrm{~K}$. The emissivity of SFRM is taken as 0.8.

The mechanical behaviour of structural steel follows the model of the Eurocode 2]. A loss of residual yield strength of $0.3 \mathrm{MPa} /{ }^{\circ} \mathrm{C}$ is assumed for steel once it has been heated beyond $600^{\circ} \mathrm{C}$. Below this temperature of $600{ }^{\circ} \mathrm{C}$, the steel strength is considered as reversible, which means that the strength is recovered to the full initial value during cooling if the temperature in the steel has not exceeded $600^{\circ} \mathrm{C}[11$.

For concrete, residual thermal expansion or shrinkage is taken into consideration when the concrete returns to the ambient temperature, the value of which is taken as a function of the maximum temperature 
according to experimental tests published in the literature [5]. As prescribed in [3], an additional loss of $10 \%$ of the concrete compressive strength is considered during cooling, with respect to the value at the maximum temperature that was reached. This additional reduction during cooling is supported by many experimental studies 12. The Explicit Transient Creep Eurocode model is adopted to take into account the transient creep strain irreversibility during cooling [7].

For wood, the numerical calculations are made in accordance with the advanced calculation method of Annex B of the Eurocode [4], based on the theory of heat transfer by conduction. The emissivity and convection coefficient are taken equal to 0.8 and $35 \mathrm{~kW} / \mathrm{m}^{2}$, respectively. The conductivity, the specific heat and the density vary with temperature following the EC5 relationships. The moisture content and the density at ambient temperature are assumed to be $12 \%$ and $450 \mathrm{~kg} / \mathrm{m}^{3}$, respectively. The temperature dependent relationships of Eurocode 5 were adopted for strength and stiffness. Accordingly, the strength and the stiffness of softwood start to decrease as soon as the temperature exceeds $20^{\circ} \mathrm{C}$, and they reduce to zero at $300^{\circ} \mathrm{C}$. It is assumed that the thermal and mechanical properties are not recovered during cooling; they keep the value corresponding to the maximum temperature that was reached. More details about the modelling assumptions for wood under natural fire exposure are given in [10].

\subsection{THERMO-MECHANICAL NUMERICAL SIMULATIONS}

The objective of the simulations is to assess the response of the structural member during the course of the natural fire. For a given structural member, numerical simulations are run under different natural fire exposures (see Figure 1).

When a member is exposed to a natural fire, its loadbearing capacity decreases during the heating phase of the fire, and it also decreases after the maximum gas temperature is attained, finally reaching a minimum value (in some cases, this may occur long after the temperature in the atmosphere is back to ambient). Then, the load-bearing capacity may remain constant or eventually recover partially or completely when the temperatures in the structure are back to ambient. This delayed decrease in load-bearing capacity may be caused by a combination of various phenomena, including the delayed temperature increase in the sections due to thermal inertia and non-recovery or additional loss of material mechanical properties during cooling [9]. For example, Figure 3 shows the results of three numerical simulations conducted on the $\mathrm{RC}$ column exposed to a natural fire with a duration of the heating phase of 60 minutes. What is plotted is the evolution of the vertical deflection at the top of the column with time. The applied loads on the column (held constant during the fire) correspond to load ratios (LR) of $55 \%, 60 \%$ and $65 \%$, respectively. As can be seen, an LR of $65 \%$ leads to structural failure after 78 minutes. Note that this means that failure arises during the cooling phase (since the natural fire has a 60-minute heating phase). However, when subjected to an LR of $60 \%$, the column fails after 241 minutes. This is a significant delay in relation to the end of the fire. Finally, the column does not fail under an LR of $55 \%$ (note that the simulation was run for 16 hours to check that the column does not fail, but the scale of the x-axis has been limited for the sake of clarity). As a result, the load-bearing capacity remains constantly greater than $55 \%$ of the capacity at ambient temperature when this column is exposed to this particular natural fire.

Figure 4 shows the evolution of temperature in the section of the RC column exposed to the 60- minute natural fire. The maximum temperature in the corner steel rebars (A) is reached after 92 minutes, i.e., during the cooling phase of the fire. It is at a level of $596{ }^{\circ} \mathrm{C}$ at that time. Hence, the corner rebars reach their minimum load-bearing capacity after 92 minutes. In the core of the concrete section $(\mathrm{C})$, the maximum temperatures are reached long after the end of the fire. This means that the concrete part of the section continues to lose part of its mechanical properties after the gas temperature in the compartment has returned to ambient. In addition, this concrete will lose an additional $10 \%$ of its strength later on, during cooling. This delayed temperature increase in the rebars and in the concrete helps to explain the delayed failure observed in Figure 3 .

Similar analyses are conducted for the other members (a steel column, a timber beam) and for varying natural fire curves and applied load ratios. The results are analysed in Section 4, after introducing a suitable indicator in Section 3.

\section{Duration of the heating Phase (DHP) INDICATOR}

\subsection{ThEORETICAL DEFINITION OF THE INDICATOR}

The key idea behind the proposed indicator is to relate the applied load ratio on a member with the duration characteristic of a natural fire, just as the fire resistance rating $(\mathrm{R})$ relates the applied load ratio with the duration of exposure to a standard fire until failure. In the case of a natural fire, the characteristic duration is chosen as the duration of the heating phase (DHP), which is equal to $t_{\max }$. For a given member, subjected to a given natural fire, one can assess the evolution of the load-bearing capacity during the course of the natural fire. To do so, several simulations are successively run until failure for varying levels of applied load (maintained constant during the fire). At time of failure, the applied load is equal to the load-bearing capacity. For example, for the RC column shown in Figure 3 , the load-bearing capacity ratio is $60 \%$ after 


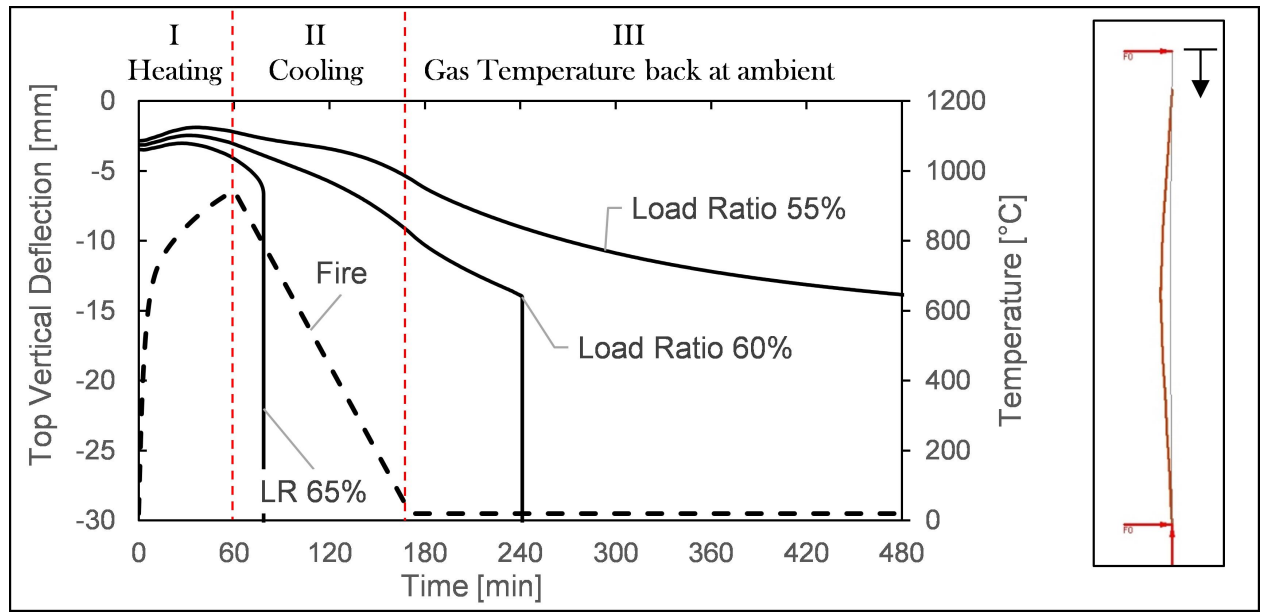

FIgURE 3. Time evolution of the top vertical displacement for an RC column exposed to a 60-minute heating phase natural fire, for different levels of applied compressive load.

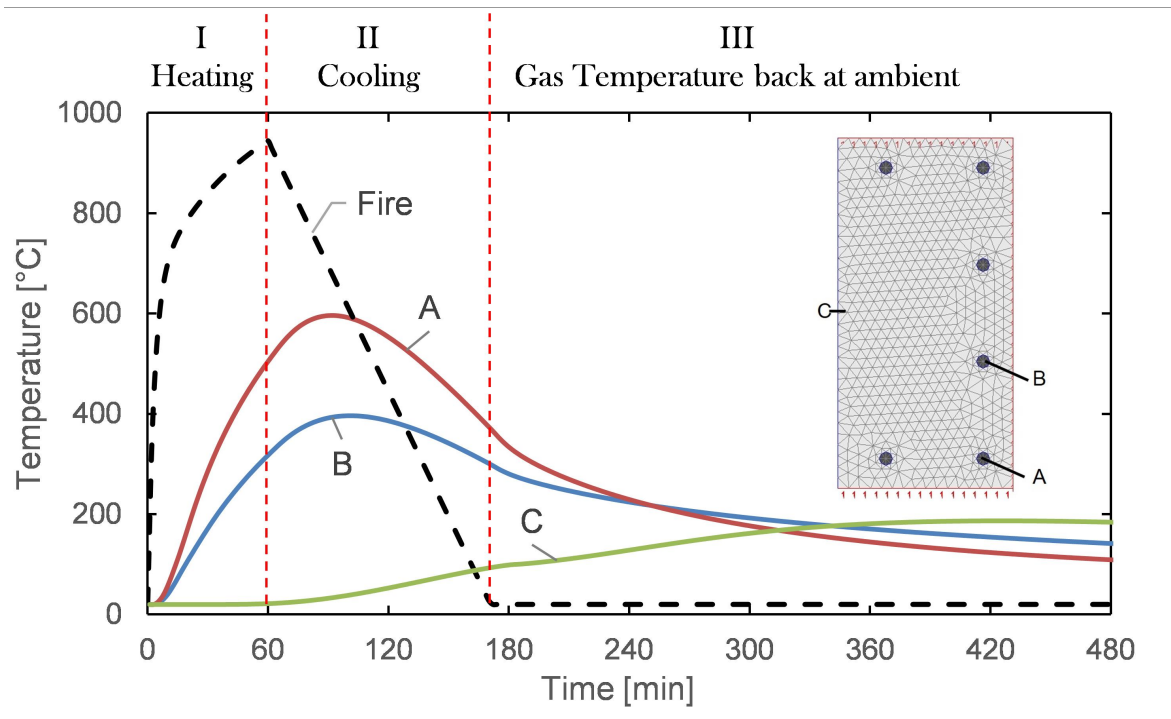

FigURE 4. Evolution of temperature in the section of an RC column exposed to a 60-minute heating phase natural fire.

241 minutes. The time evolution of the load-bearing capacity is thus obtained point-by-point as the result of several simulations run until failure.

Figure 5 shows, for the RC column, the evolution of the load-bearing capacity under different fire exposures: natural fires with $\mathrm{DHP}\left(t_{\max }\right)$ of $30 \mathrm{~min}$, $60 \mathrm{~min}$ and $120 \mathrm{~min}$, and the standardized ISO fire. When subjected to the ISO fire, the load-bearing capacity decreases continuously as a result of continuously increasing gas temperatures. However, in the case of natural fire exposure, the load-bearing capacity reaches a minimum value, after which it will remain constant or will recover. In Figure 5 the last point of the curves for natural fires corresponds to the minimum value of the load-bearing capacity that is reached under the corresponding natural fire. Beyond this point, the load-bearing capacity may remain constant or increase.

It is interesting to relate this minimum value of the load-bearing capacity with the DHP of the natural fire. For example, for the RC column, the load-bearing capacity reaches a minimum of $72 \%$ when subjected to a natural fire with DHP of 30 minutes. This means that, if the applied LR is lower than $72 \%$ and the member is subjected to this fire, it will survive the total duration of the fire, until complete burnout. Inversely, if the applied LR is higher than or equal to $72 \%$, the RC column will fail due to the fire. On the other hand, if the applied LR is $72 \%$, one can also say that the column will fail if it is exposed to a natural fire with a DHP of at least 30 minutes. Hence, the DHP indicator is based on the minimum duration of a fire heating phase that affects the structural component to such an extent that it will fail even if the fire stops after that time.

As is shown in Figure 5 the DHP indicator can thus be derived from the load-bearing capacity curves, by relating the minimum value of the capacity to the duration of the heating phase of the natural fire (which is as defined in Figure 1). By definition, the DHP of a 


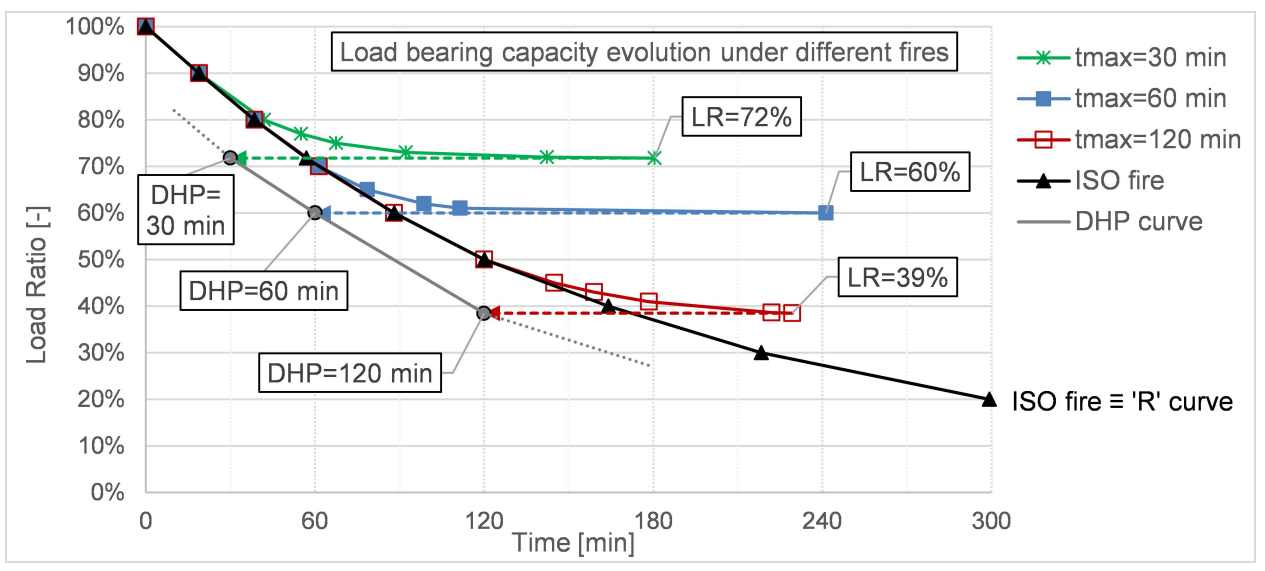

FiguRE 5. Evolution of the load-bearing capacity of an RC column under different fire exposures. The RC column loaded at $72 \%$ of its maximal capacity at ambient temperature has DHP of $30 \mathrm{~min}$ and R of $57 \mathrm{~min}$.

member under a given applied LR represents the minimum exposure time to a standard ISO fire (followed by the cooling phase, in accordance with the Eurocode parametric fire model), which will eventually result in failure of the structural component. This value is always smaller than or equal to the Fire Resistance R.

\subsection{Methods For obtaining the DHP of A STRUCTURAL MEMBER}

The method for obtaining the DHP of a structural member subjected to a given load ratio is illustrated by the flowchart in Figure 6. It can be seen that this method is a more complex operation than the method for obtaining the Fire Resistance, for two reasons.

First, searching for the DHP of a member means searching for a fire curve. The process is therefore iterative, and consists of several analyses under different applied parametric fires for a search for the minimum value of parameter $t_{\max }$ that leads to structural failure. Because of the iterative procedure, experimental testing is not practically applicable; analytical or numerical models must be used. Secondly, except for the simplest members, the analysis of a structural member under natural fire necessarily requires a verification in the entire time domain by a step-by-step iterative method, since verification in the load domain at the time of maximum gas temperature does not guarantee against failure at a later stage. The "thermal analysis" and the "mechanical analysis" in the flowchart therefore need to be transient analyses. These are usually performed by means of advanced numerical methods, such as the non-linear Finite Element Method (FEM).

Figure 6 presents a flowchart for obtaining the DHP in the simplest way possible. However, this flowchart can be optimized for practical applications. For example, the initialization can be done for a value of $t_{\max }$, which is more likely to approximate the DHP (e.g., instead of starting with $t_{\max }=0$, one could start with $t_{\max }=45 \mathrm{~min}$ ). If the member fails, the value of $t_{\max }$ is decreased by $t_{\text {step. }}$. The process is repeated until $t_{\max }$ is such that it no longer leads to failure. The last (i.e., smallest) value of $t_{\max }$ that caused failure of the structural member is the DHP.

The parameter $t_{\text {step }}$ is related to the degree of accuracy in determining DHP. The larger $t_{\text {step }}$ is, the smaller the number of iterations to find DHP, but in the meantime the smaller the degree of accuracy in DHP. Therefore, this parameter should not exceed a few percent of the value of DHP.

For a structural member, the DHP depends on the applied load ratio. The relationship between the DHP and the load ratio can be obtained by applying the method of Figure 6 for several different values of the load ratio, and then interpolating between the points to construct the "DHP curve" of the member (see Figure 5.

The method given in Figure 6 is generally not the most efficient for constructing the DHP curve of a structural member. Indeed, for each point of the curve, it requires multiple thermal and mechanical analyses to be run. For practical applications, the alternative method of Figure 7 can be preferred. In this alternative method, the thermal analysis is brought out of the loop; the number of thermal analyses to be run is therefore reduced to the number of points of the DHP curve to be computed.

The two different methods for constructing the DHP curve are illustrated schematically in Figure 8 The method of Figure 6, referred to as the "fixed load ratio method", allows us to compute the DHP of a member subjected to a given load ratio. In contrast, the "fixed fire curve" method of Figure 7 starts by considering a given fire curve (with its DHP), and then searches for the load ratio associated to this DHP. It is recommended to initialize LR at $100 \%$ and then to decrease its value until the minimum is found that leads to failure. Indeed for high values of $L R$, the step-by-step analysis only needs to simulate for a few minutes before failure occurs. The "fixed fire curve" method can be repeated for different fires in order to construct the DHP curve of a member. 


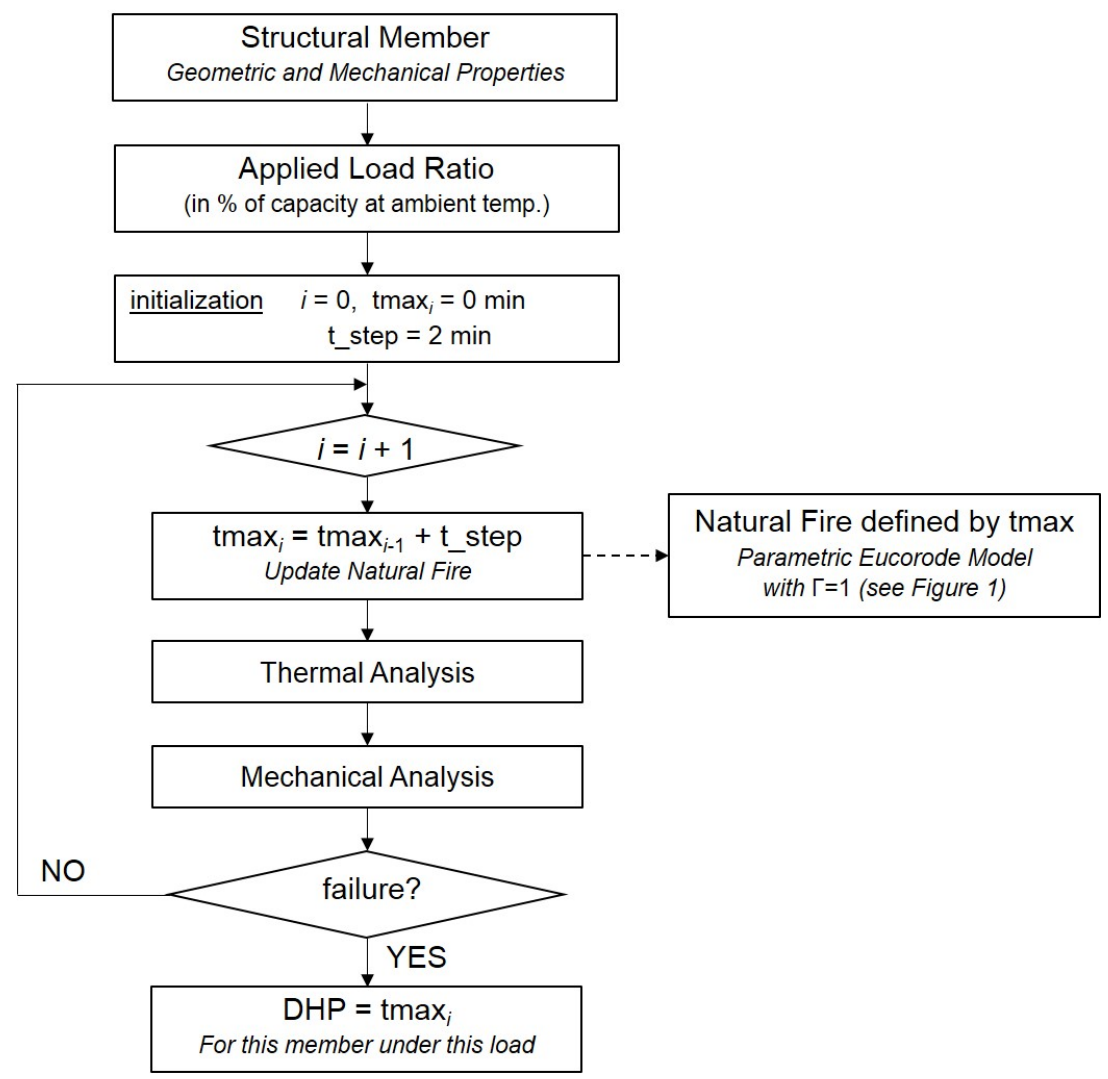

FIgURE 6. Flowchart to obtain the DHP of a member - fixed load ratio method.

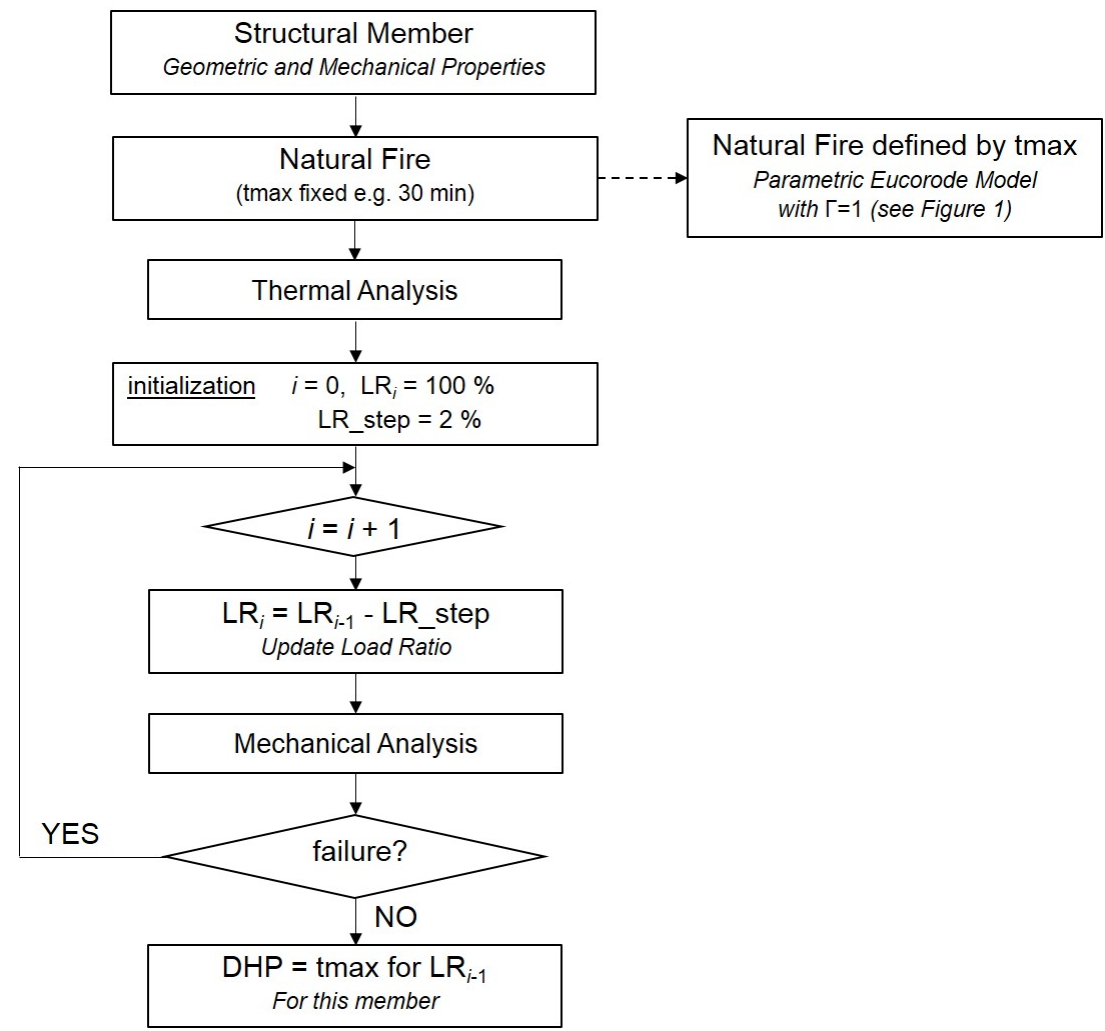

FIGURE 7. Flowchart to obtain the DHP of a member - the fixed fire curve method. 


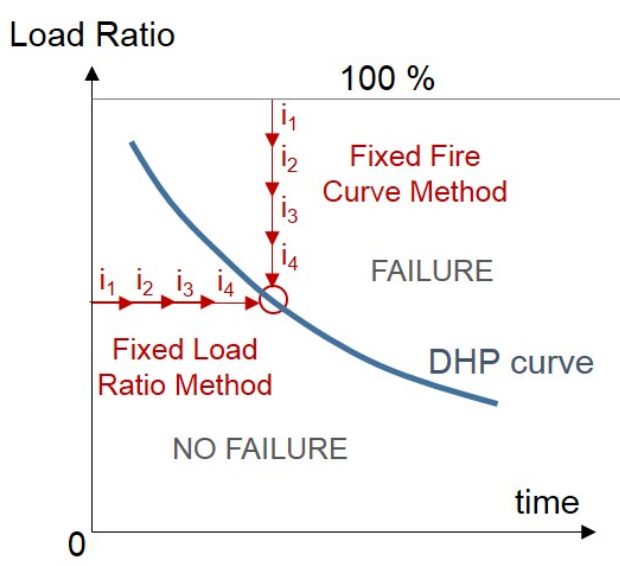

Figure 8. Two methods are proposed for obtaining the DHP of a member: the Fixed Load Ratio Method, and the Fixed Fire Curve Method.

\subsection{Practical interpretation OF DHP}

The indicator DHP quantifies the sensitivity of structural members to fire decay phases. It is intended for use in conjunction with the Fire Resistance rating (R), to complement the information carried by $\mathrm{R}$.

$\mathrm{R}$ and DHP are standardized indicators, and as such they are useful for comparing and classifying different structural members. For a member, the difference (in time) between DHP and R indicates the sensitivity to decay phases. For identical R, the lower the DHP of a member, the higher its propensity to delayed failure. In terms of performance-based design, the Fire Resistance indicator is interpreted as information about the time of resistance during the heating phase of a fire. However, it is obviously not a direct measure of this time, since the real fire conditions will differ from the prescriptive fire conditions. DHP is interpreted as information about the occurrence of delayed failure as a function of the instant when the fire started to decrease, whether by self- extinction or due to the action of firefighters.

The characterization of a structural member by a pair of indicators (DHP, R) has important practical implications, in particular for firefighters . On a practical level, the pair of indicators (DHP, R) allows the post-flashover time domain to be divided into three parts for a structure in fire (at least if the temperature development in the post-flashover phase is within the order of magnitude of the standardized fire). For example, consider the timeline of Figure 9, on which the indicators have been plotted for the $\mathrm{RC}$ column discussed in Section 3.1 under a load ratio of $60 \%$. This column has DHP of $60 \mathrm{~min}$ and $\mathrm{R}$ of $88 \mathrm{~min}$. The three parts of the time domain can then be interpreted as follows:

(1.) The first part of the time domain starts at the flashover and lasts until the time corresponding to DHP. In this part, the structure is theoretically safe. It is able to withstand the effects of the fire and,

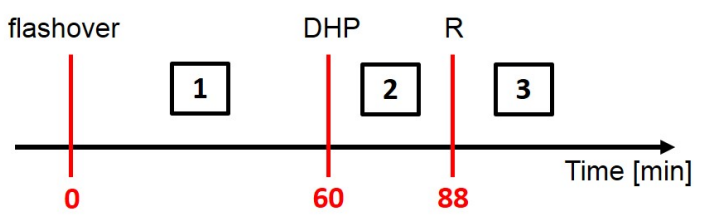

Figure 9. On a timeline representing the postflashover time of heating, DHP marks the point of no return, from which the structure has been affected to such an extent that it will fail even if the fire stops thereafter.

if the gas temperature starts cooling down in this part, the structure will survive indefinitely.

(2.) The second part of the time domain lies between the times corresponding to DHP and R. In this part, the structure is still standing even if the gas temperature has been continuously increasing from the flashover. However, if the fire is still in its heating phase, the structure has been affected to such an extent at that time that it will fail, even if the fire stops shortly thereafter.

(3.) The third part of the time domain starts at the time corresponding to $\mathrm{R}$. In this part, if the gas temperature has not started cooling down yet, the structure is theoretically collapsed.

This discussion illustrates the major significance of DHP: it marks a point of no return for the structure. If the gas temperature has not started cooling down at the time of DHP, the structure will collapse in due course. This means that the DHP of a structure is key information for firefighters. When arriving on site, they can relate DHP with the information they can get about the duration of the fire, and they can use it for mitigating the risk during their intervention. If the duration of the fire (i.e., the post-flashover time of heating) has exceeded the DHP of the structure, the firefighters must take special care, because structural failure is most likely to occur despite any intervention they may make to extinguish the fire.

Finally, it is important to note that DHP gives no indication about the time of collapse. Generally, collapse can occur several minutes or hours after the time corresponding to DHP, and it may even occur after the end of the fire, when the temperature in the compartment is back to ambient.

\section{Analysis of the Results USing THE DHP INDICATOR}

Table 1 summarizes the results of the numerical simulations performed in Section 2. For the 4 members analysed in this paper, the table gives the DHP and the Fire Resistance $\mathrm{R}$ under different applied load ratios. For example, for the RC column under $40 \%$ applied LR, the DHP is equal to $116 \mathrm{~min}$, while the fire resistance is $164 \mathrm{~min}$ (which is also shown in Figure 5). 


\begin{tabular}{|c|c|c|c|c|c|c|c|c|}
\hline \multirow[t]{2}{*}{ Load Ratio } & \multicolumn{2}{|c|}{ RC column } & \multicolumn{2}{|c|}{ Steel Column (P1) } & \multicolumn{2}{|c|}{ Steel Column (P2) } & \multicolumn{2}{|c|}{ Timber Beam } \\
\hline & DHP & $\mathrm{R}$ & DHP & $\mathrm{R}$ & DHP & $\mathrm{R}$ & DHP & $\mathrm{R}$ \\
\hline $60 \%$ & 60 & 88 & 35 & 54 & 72 & 108 & 15 & 51 \\
\hline $50 \%$ & 89 & 120 & 43 & 61 & 84 & 120 & 26 & 71 \\
\hline $40 \%$ & 116 & 164 & 50 & 69 & 97 & 135 & 39 & 92 \\
\hline $30 \%$ & 168 & 218 & 60 & 79 & 111 & 153 & 53 & 116 \\
\hline
\end{tabular}

TABLE 1. Indicators R and DHP for the structural members under different load ratios (in minutes).

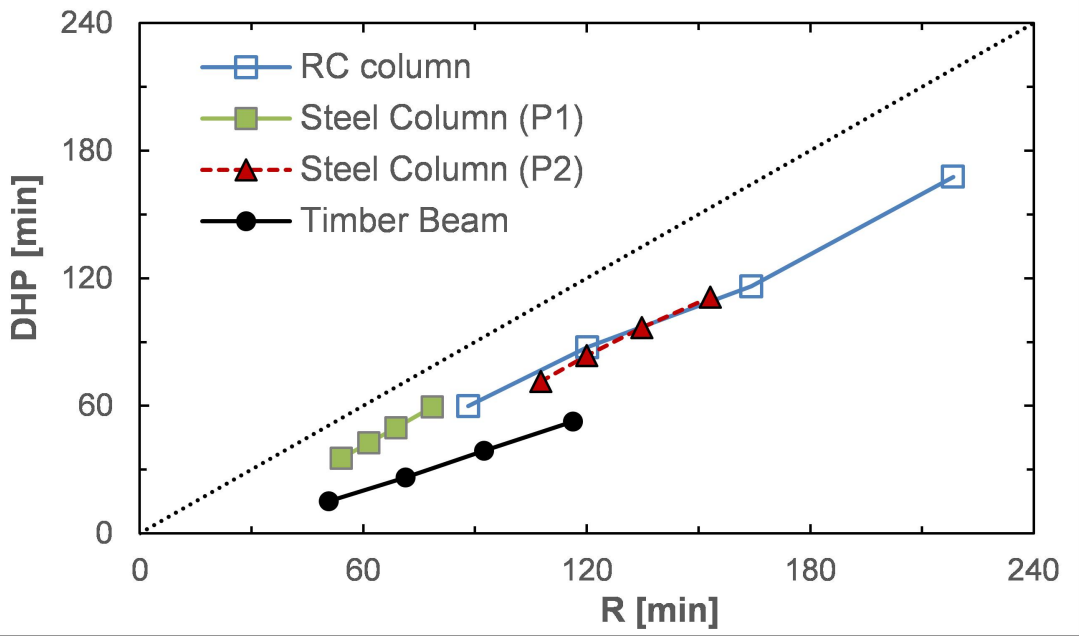

Figure 10. The distance from the bisector in the R-DHP space reflects the propensity to delayed failure.

The results of Table 1 are plotted in Figure 10 This leads to the following main observations:

- The DHP is always lower than the Fire Resistance. Indeed, all points are located below the bisector in the R-DHP space. This reveals the possibility of delayed failure for all the members studied here.

- The difference between DHP and R is higher for certain members (e.g., Steel column P2) than for others (e.g., Steel column P1). It is also higher for the timber beam. This reveals the effects of different mechanisms that influence delayed failures, e.g., thermal inertia due to steel thermal insulation (P2 has more insulation than P1), and the delayed charring process in a timber member. A structural member with a response in the R-DHP space that is far removed from the bisector has a high propensity to delayed failure.

- It is possible for two structural members to have the same $\mathrm{R}$ (under given load ratios) but a different DHP. The member with the largest DHP has the advantage of performing better under natural fire. As an example, Figure 11 plots on a timeline the results (DHP, R) corresponding to an LR of $50 \%$ for the steel column $\mathrm{P} 1$ and the timber beam. The timber beam has a higher $\mathrm{R}$ but a lower a DHP than the steel column. Therefore, under natural fire, there is actually a higher probability of failure of the timber beam than of the steel column. Indeed, natural fires with a duration of the heating phase of between 26 minutes and 43 minutes would lead to failure of the timber beam, but they would not cause failure of the steel column. If $\mathrm{R}$ was the only indicator considered, one would disregard entirely the higher sensitivity to cooling phases of the timber beam and conclude that the safety level is higher for the timber beam than for the steel column P1 (since $\mathrm{R}$ is higher). However, Figure 11 shows that this is not true under natural fire exposure. It is therefore necessary to use DHP, in conjunction with Fire Resistance $\mathrm{R}$, to get a comprehensive evaluation of the performance of a structural member when considering natural fires.

\section{Conclusions}

Delayed structural failures arising during or after the cooling phase of a fire, may occur with all types of structural members and constituting materials. They result from various mechanisms, e.g., the effects of thermal inertia or the additional loss of mechanical properties during cooling. The possibility of delayed failures must be correctly assessed when considering more realistic fire scenarios, especially for a better assessment of safety during interventions by firefighters.

This study has led to a proposal for a method for deriving an indicator, DHP, which is a pragmatic measure that can be used to compare different structural members in terms of their propensity to delayed failure. On a practical level, the pair of indicators (DHP, R) allows the post-flashover time domain to be 


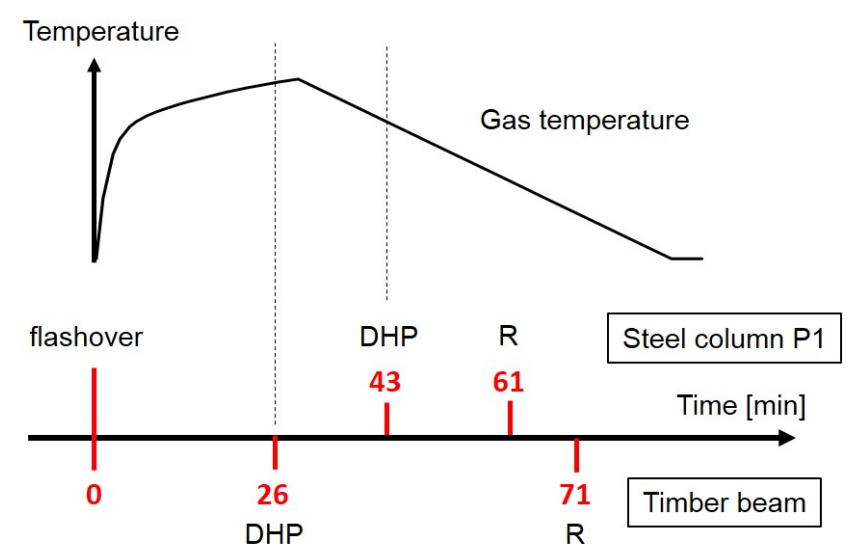

Figure 11. Comparison of fire performance for the steel column P1 and the timber beam, given an applied LR of $50 \%$ on the member. Based on DHP analysis, natural fires with a duration of the heating phase of between 26 min and $43 \mathrm{~min}$ lead to structural collapse of the timber beam but not of the steel column.

divided into three parts for a structure in fire, at least if the temperature development in the post-flashover phase is in the order of magnitude of the standardized fire. As long as the heating time that has elapsed after flashover is shorter than DHP, the structure is theoretically safe; as soon as it exceeds DHP, the structure has been affected to such an extent that it will fail, even if the fire stops subsequently; and when the post-flashover time of heating exceeds $R$, the structure is theoretically collapsed. This information may be valuable for firefighters, who will be able to use it when they arrive on site in order to mitigate the risk during their interventions.

For future works, our research should be extended from the scale of a member to the scale of a structure. This is necessary because particular characteristics of a structure, e.g., joints between different members, are expected to exhibit a significant sensitivity to cooling.

\section{REFERENCES}

[1] EC1. 2002. EN 1991-1-2. Eurocode 1: Actions on Structures - Part 1-2: General actions - Actions on structures exposed to fire. Brussels: CEN.

[2] EC3. 2005. EN 1993-1-2. Eurocode 3 - Design of steel structures - Part 1-2: General rules - Structural fire design. Brussels: CEN.

[3] EC4. 2005. EN 1994-1-2. Eurocode 4 - Design of composite steel and concrete structures. Part 1-2: General rules - Structural fire design. Brussels: CEN.

[4] EC5. 2004. EN 1995-1-2. Eurocode 5 - Design of timber structures - Part 1-2: General - Structural fire design. Brussels: CEN.
[5] Franssen J. M. 1993. Thermal elongation of concrete during heating up to $700{ }^{\circ} \mathrm{C}$ and cooling. University of Liege. http://hdl.handle.net/2268/531 [2016-10-01].

[6] Franssen J. M. 2005. SAFIR: A thermal/structural program for modeling structures under fire. Engineering Journal - American Institute of Steel Construction, 42(3), p. $143-158$.

[7] Gernay T. 2012. Effect of Transient Creep Strain Model on the Behavior of Concrete Columns Subjected to Heating and Cooling. Fire Technology, 48(2), p. 313-329. DOI:10.1007/s10694-011-0222-0

[8] Gernay T, Franssen J. M. 2012. A formulation of the Eurocode 2 concrete model at elevated temperature that includes an explicit term for transient creep, Fire Safety Journal, 51, p. 1-9. DOI:10.1016/j.firesaf.2012.02.001

[9] Gernay T, Dimia M. S. 2013. Structural behaviour of concrete columns under natural fires, Engineering Computations, 30(6), p. 854-872. DOI:10.1108/ec-05-2012-0103

[10] Gernay T, Franssen J. M. 2015. A performance indicator for structures under natural fire, Engineering Structures, 100, p. 94-103. DOI:10.1016/j.engstruct.2015.06.005

[11] Kirby BR, Lapwood D.G., Thomson G. 1986. The reinstatement of fire damaged steel and iron framed structures. London, UK: B.S.C., Swinden Laboratories. 0900206462

[12] Yi-Hai L, Franssen J. M. 2011. Test results and model for the residual compressive strength of concrete after a fire, Journal of Structural Fire Engineering, 2(1), p. 29-44. DOI:10.1260/2040-2317.2.1.29 